\title{
Identity Formation: Role of Social Support and Self Esteem among Indian Adolescents
}

\author{
Sarla Devi ${ }^{1 *}$, Dr. Jyotsana ${ }^{2}$
}

\section{ABSTRACT}

The term identity is very important for adolescents. Adolescence is a time to sum up one's past and current experience to arrive at a sense of identity, which in turn will guide one's future plans. Adolescence has been considered as a period marked with identity crisis. Who am I all about? What am I going to do with my life? What is different about me? How can I make it on my own? These questions are usually considered in adolescence. Adolescents are keen for solutions to questions of identity. Identity has been called a "sense” an "attitude” a "resolution" and so on. The term social support means the person seeks help and support from friends, the term self esteem means the belief about their own self. Self-esteem is a socio psychological construct that assesses an individual's attitudes and perceptions of self-worth. For this purpose a sample of 150 adolescents (75 boys and 75 girls) ranging in age from of 14 to18 years, were selected from various schools of Hisar, Haryana (India).They were administered (EOMEIS-2; Bennion and Adams, 1986), Perceived Social Support Assessment (Zimet, Dahlem, Zimet \& Farley, 1988), Self Esteem Scale (Rosenberg, 1965). The result has been discussed and shown in tables.

Keywords: Identity formation, Self Esteem, Social Support, Adolescent.

Identity in adolescent is important because it is the first time that physical development, cognitive skills and social expectations coincide to enable young person to sort through and understand childhood identifications in order to construct a viable pathway toward their adulthood. Erikson (1968) portrayed of identity formation. He described identity as the central developmental task of adolescence. But identity neither begins nor ends with adolescence. It begins with the self-object differentiation at infancy and reaches its final phase with the selfmankind integration at old age. He suggested that identity is ideally experienced as sense of well being, and those who have a secure identity, feel 'at home' with themselves, and are confident about knowing their place and direction in life. An individual in his/her identity strives to feel good about the self. Any disturbance in the process of identity formation will lead to many

\footnotetext{
${ }^{1}$ Research Scholar in the Department of Applied Psychology at GJU S\&T Hisar

${ }^{2}$ Professor in the Department of Applied Psychology at GJU S\&T Hisar

*Responding Author

(C) 2016 I S Devi, Jyotsana; licensee IJIP. This is an Open Access Research distributed under the terms of the Creative Commons Attribution License (http://creativecommons.org/licenses/by/2.0), which permits unrestricted use, distribution, and reproduction in any Medium, provided the original work is properly cited.
} 
consequences including time confusion, extramarital affairs, role confusion, choosing a negative identity, tendency to excel in all the situations, generalized doubt, and uncertainty. Adolescence may move towards two poles: identity achievement and identity confused. In adopting Erikson's concept of identity for empirical research, Marcia (1966) identified exploration and commitment, as the two basic dimensions for defining the individual status with respect to achieving an identity. By simultaneously considering an individual's levels of exploration and commitment, Marcia (1966) was able to derive four statuses for characterizing an individual's development toward a mature identity. These statuses are: Achievement, Moratorium, Foreclosure, and Diffusion. Achievement is characterized by a period of active exploration leading to a firm set of identity commitments. Foreclosure is characterized by strong commitments enabled without much exploration of other possible alternatives. Moratorium refers to active exploration of other possible alternatives. But individuals are in a state of uncertainty regarding life choices. Diffusion refers to adolescents who don't actively explore different alternatives and who look strong commitments. Identity diffused individuals seem to drift aimlessly and are carefree. For adolescents perceived social support play an important role to form the identity.

Perceived social support can be described as the social and psychological support provided by the environment. It can said that the experience or the perception being cared for, valued, included and/or guided by others, especially from ones family, peers and friends and /or community members. (Luyckx, et.al. 2006) suggest that support and opportunities offered by an individual environment have a large influence on identity formation. Social support from peers, teachers, parents, has been recognized as a protective factor for teens (Benard, 2004). Social support is a supportive relationship with others (DuBois, et al., 2002). Gallagher, K. et al. (2002) found that sometimes these relationships act as resources encouraging favorable adjustment in adolescents. Particularly in adolescents, strong the interpersonal relationships are beneficial because they function as a source of comfort and safety throughout the multiple life changes that occur during this stage of development. Basically two types of support are found that have the greatest influence on the individual: family and peers. Familial stimulate and support the development of distinctive points of view; peers offer models, diversity and opportunities for exploration of beliefs and values (Bosma \& Kunnen, 2001). The relationships with one's family are the most typical one that one experience at the first time and play an important role in the early stage of identity development. They supported the idea that familial interactions influence the initial status of identity formation. They also found that family is the base for the values and beliefs. Family and individual relation quality also influence the identity formation. They found that friends affect identity formation by solving one developmental crisis. Berndt (2004) explain that friend influence important attitudes, behavior and characteristics of adolescents. He found that individual who do not have positive relationship with friends also experience conflict and remain in identity formation foreclosure stages. Acc. to Fulton, (1997) study shows that subjects high on identity diffusion have been reportedly high on self-related problems and alienation. Research suggests that identity diffusion is associated with many maladaptive patterns ranging from mild emotional problems to severe psychopathology (Ball and Chandler, 1989; White and 
Johness, 1996; Sandhu and Tung, 2004). Sherbaf, (2003) found that people who have achieved an identity tend to be introvert and cognitively perform well under stressful situations. They remain poised when exposed to sudden environmental changes. They are light-hearted and are open to new experiences. A number of study has been conducted by (Cameron, 1987; Clancy and Dollinger, 1993; Marcia, 1993 and Luyckx, 2005) empathized that Adolescents in the diffusion status demonstrated low emotional stability and conscientiousness, and moderate levels of openness to experience. Individuals in the diffusion status reported moderate levels of adjustment, as compared to the other statuses. This continued exploration may lead to a sense of floundering and procrastination than others. That can adversely affect mental health. Adams, et al. (2005); Luyckx, et al. (2005) found that identity diffused tends to be associated with low self esteem, delinquency, and drug or alcohol problems. Acc. to Shahraray, (2005) people with achieved identity are more successful, reliable, adaptable, efficient, and individually more cohesive and enjoy a higher level of mental health. (Hashemi,2006; Omidian,2009; Farzanekhoo, et al.2009) studies suggested that diffused identity can lead to aberrant behaviors such as recourse to drugs, abandoning home, and getting involved in illegal or unconventional activities. Krogen, et al. (2010) consider that this anxiety to short-lived because moratorium is a transitional period of personal reflection before reaching identity achievement. Specifically, adolescents in the achievement and foreclosure statuses exhibited better emotional adjustment than their moratorium peers.

Blascovich \& Tomaka, (1991) defined Self-esteem is a widely used concept both in popular language and in psychology. It refers to an individual's sense of his or her value or worth, or the extent to which a person values, approves of, appreciates, prizes, or likes him or herself selfesteem is "an understanding of one's quality as an object-that is, how good or bad, valuable or worthless, positive or negative, or superior or inferior one is"' (Thoits, 1999). For people of all ages, the development of full human potential is enhanced through high self esteem. (Adams and Shea, 1979; Marcia, 1967; Podd, 1972; cited in Omidian, 2009) studies revealed that identity has been associated with more complex personality characteristics such as self esteem, locus of control, and higher-level moral reasoning. Perlin, et.al. (1981) found that individuals who have high perceptions of self-worth and self-esteem are thought to cope better with stress. Rosenberg, (1985) and Rosenberg, et.al. (1989) found that self-esteem is strongly and negatively correlated with distress and depression. Redenback, (1991) explained that high self esteem can begin to develop when the acceptance of all individuals and their personal and group contributions are recognized and applauded, especially in a multi-culturally diverse world. Alison studies revealed that people with poor self-esteem demonstrate physical complaints, antipathy, loneliness, depression, and despair (Biabangard, 1993; cited in Pourghaznein and Ghafari, 2004). A study by Taylor and Oskay (1995) found that there is significant relationship between identity status and self-esteem. Marcia, (1993) and Kroger, (2003) found that Foreclosed adolescents are somewhat lower than achieved adolescents in self-esteem, but they show few symptoms of depression and diffused adolescents score low on self-esteem and high on measures of depressed mood. Berman, et.al. (2006) depicted that moratorium adolescents generally have lower self- 
esteem and showed high levels of depressed mood and anxiety because of their continuing exploration. Berndt (2002) found that these positive characteristics like loyalty, trust, intimacy and self disclosure in friendship are correlated with higher self esteem.

Identity formation among adolescents is a lifelong process but it started to take shape during adolescents. Therefore it has been proved statistically that identity formation is associated with self esteem and social support. If an adolescents perceived proper social support and have high self esteem then the adolescent will develop the achieved and moratorium type of personality.

\section{RATIONALE OF THE STUDY}

Adolescent is a time of enjoyment, energy, enthusiasm, autonomy, excitement, pleasure, identity formation and growth. Adolescent are full of energy so it is required that it should be channelized in more constructive and positive manner so that they become an effective adult and leads a prosperous life.

Self esteem plays an important role in the development of an identity. When adolescents started to evaluate positively then it leads to achieved identity. So high self esteem leads develop achieved form of identity.

Social support is an important aspect that plays an important role during adolescent stage. During adolescent peer play an important role in the formation of identity.

The present study mainly focuses on identity formation and the role of self esteem and social support. The researches depicted that social support and self esteem played an important role in the formation of identity.

\section{OBJECTIVES}

After reviewing the past research following objectives were formed:

1) To study the relationship between identity formation and social support among adolescents.

2) To investigate the relationship between identity formation and self esteem among adolescents.

3) To study the difference in identity formation between girls and boys.

4) To study the difference in self esteem between girls and boys.

5) To study the difference in social support between girls and boys.

\section{Hypotheses}

On the basis of the research purpose following hypotheses was formed.

1. It is assumed that identity formation is associated with social support.

2. It is expected that identity formation is associated with self esteem.

3. It is assumed that there is difference between male and female adolescents on identity formation.

4. It is assumed that there is difference between male and female adolescents on social support. 
5. It is assumed that there is difference between male and female adolescents on self esteem.

\section{METHODS}

The sample was consisted of 150 adolescents ( 75 boys and 75 girls).The sample was randomly selected from different schools of Hisar in Haryana.

\section{Tools}

1. Extended Objective Measure of Ego Identity Status-2: (EOMEIS-2; Bennion and Adams, 1986) has been used for assessment of identity formation. It has 64 items and assesses the identity formation of an individual in two domains- ideological domain and interpersonal domain (32 items in each domain). Ideological domain consist the area of occupation, religion, politics, and philosophical life style (8 items in each area) and interpersonal domain consist the area of friendship, recreation, dating and sex roles (8 items in each area). Both the domain assesses the four status of identity like - achievement, moratorium, foreclosure and diffusion. In this study 48 items were used. 16 items from the interpersonal domain (dating and sex roles) were eliminated. These domains were not permit according to culture of the organization. The reliability coefficient (EOMEIS-2) ranging from .72 to .87 on Indian culture. This scale contains predictive, concurrent and content validity.

2. Perceived Social Support Scale This multidimensional scale of (Zimet, Dahlem, Zimet \& Farley, 1988) is a 12 items questionnaire that evaluated the participant's perception of the role that friends, family and peers play in their lives. Each item can be scored from 1 to 7 where 1 denotes very strongle disagree,2 denotes strongle disagree, 3 denotes mildly disagree, 4 denotes neutral, 5 mild agree, 6 as strongly agree and 7 as very strongly agree. The scale is developed to use any kind of sample.

3. Self esteem scale (Rosenberg, 1965) has been used to measure the self esteem of the subject in this study. It has 10 items that measure the global self esteem. The items are answered on a four-point scale ranging from strongly agrees to strongly disagree. There are five items which are reversed scored where $S A=1, A=2, D=3, S D=4$. The scored items are calculated and high score represented high self esteem and lower score represented lower self esteem. The scale has been shown to have a high level of reliability $(\alpha=.88)$ in adolescent populations (Barrett, Webster, \& Wallis, 1999). 
RESULTS AND DISCUSSION

\begin{tabular}{|l|l|l|l|l|l|}
\hline Variable & Achievement & Moratorium & Foreclosure & Self esteem & Social support \\
\hline Achievement & 1.00 & $.233^{* *}$ & .069 & .043 & .058 \\
\hline Moratorium & & 1.00 & $.335^{* *}$ & $-.237^{* *}$ & -.159 \\
\hline Foreclosure & & & 1.00 & -.062 & -.09 \\
\hline Self esteem & & & & 1.00 & $.26^{* *}$ \\
\hline $\begin{array}{l}\text { Social- } \\
\text { support }\end{array}$ & & & & & 1.00 \\
\hline
\end{tabular}

** Denotes the level of significant at 0.01 levels.

*Denotes the level of significant at 0.05 levels.

A significant relation was found between the achievement and moratorium status of identity $(\mathrm{r}=.233)$, significant relation was found between moratorium and foreclosure ( $\mathrm{r}=.335$ ), significant relation was found between moratorium and self esteem $(\mathrm{r}=-.237)$, significant relation was found between self esteem and social support ( $r=.26)$. Schwartz et al., (2009) found that people, who are involved in exploration, can give rise to a sense of confusion because adolescents are trying to explore the possible alternatives. As adolescents are not committed, therefore the level of self esteem goes down. Above findings are supported by number of findings. Basak \& Ghose (2008), who found that adolescents with identity achievement status have higher self-esteem whereas identity moratorium, identity foreclosure and identity diffused adolescents have lower self-esteem. Moratorium has been associated with low self-worth (Meeus, Iedema, Helsen, \& Vollebergh, 1999; Schwartz, Zamboanga, Weisskirch, \& Rodriguez, 2009). Moratorium adolescents generally have lower self-esteem and show high levels of depressed mood and anxiety because of their continuing exploration (Berman, Weems, \& Stickle, 2006).From the given result it can be said that the status of identity formation is not significantly related with social support. These findings are not following the past findings it represented that there is significant relationship between social support and identity formation. 
Identity Formation: Role of Social Support and Self Esteem among Indian Adolescents

Table 2 Difference between means on Achievement, Moratorium, Foreclosure, Diffused and Self Esteem between boys and girls.

\begin{tabular}{|l|l|l|l|l|l|}
\hline Variables & Group & N & Mean & S.D. & t-value \\
\hline \multirow{3}{*}{ Achievement } & Boys & 75 & 52.40 & 7.27 & \\
\cline { 2 - 6 } & Girls & 75 & 50.11 & 6.90 & -2.06 \\
\hline \multirow{2}{*}{ Moratorium } & Boys & 75 & 49.24 & 7.29 & \\
\cline { 2 - 6 } & Girls & 75 & 47.44 & 7.93 & -1.45 \\
\hline \multirow{5}{*}{ Diffused } & Boys & 75 & 39.92 & 11.03 & \\
\cline { 2 - 6 } & Girls & 75 & 45.69 & 9.73 & 2.20 \\
\hline \multirow{5}{*}{ Self-Esteem } & Boys & 75 & 42.37 & 6.32 & \\
\cline { 2 - 6 } & Girls & 75 & 44.65 & 6.40 & 3.40 \\
\cline { 2 - 6 } & Boys & 75 & 17.69 & 3.73 & \\
\cline { 2 - 6 } & Girls & 75 & 18.29 & 3.94 & .96 \\
& Boys & 75 & 59.31 & 13.72 & \multirow{2}{*}{1.81} \\
\hline
\end{tabular}

** Denotes the level of significant at 0.01 levels.

*Denotes the level of significant at 0.05 levels

From the above table it was depicted that there was no significant difference between means on identity formation status like achievement, Moratorium, foreclosure, diffused, self esteem and social support on male and female adolescents. There are some studies which support the above finding that adolescent boys and girls to be similar in few identity status, such as in identity achievement and identity foreclosure (Cramer, 2000). Some findings are not supported by the past research. Inverse findings are found Streititmatter (1987) that boys are more active in exploration of other possible alternatives and more uncertainty regarding life choices than girls. Cramer (2000) found that boys and girls are different in the status of identity Moratorium. A study by Archer (1982) found that no significant difference in identity status by gender. There was a significant difference in level of self esteem between boys and girls. SarAbadaniTafreshi (2006) supported the result that there is significant difference in the level of self esteem between boys and girls.

From the above finding it can be said that this research is not supporting the past research.

\section{CONCLUSION}

In aggregate, it can be said that identity formation status moratorium negatively correlated with self esteem. These findings are supporting the exiting research. It has also found that there is no significant difference between male and female adolescents on the variable of identity formation, self esteem and social support. This study has several limitation and application. This is very small sample study, so there is problem of generalization. In Indian context there were few studies on identity formation. So this study will prove very useful for further research. 


\section{REFERENCES}

Adams, G. R., Munro, B., Munro, G., Doherty-Poirer, M., \& Edwards, J. (2005). Identity processing styles and Canadian adolescents' self-reported delinquency. Identity: An International Journal of Theory and Research, 5, 57-65.

Adams, G. R., Shea, J., \& Fitch, S.A. (1979). Toward the development of an object assessment of ego-identity status. Journal of youth and adolescence, 8 (20), 223-237.

Ball, P., and Chandler, M. (1989). Identity formation in suicidal and non suicidal youth: The role of self-continuity. Journal of Development and Psychopathology.

Barrett, P. M., Webster, H. M., \& Wallis, J. R. (1999). Adolescent self-esteem and Cognitive skills training: A school-based intervention. Journal of Child and Family Studies, 8(2), 217-227.

Basak, K. \& Ghose, A. (2008). Ego identity status and its relationship with self esteem in a group of late adolescents. Journal of Indian academy of applied psychology. Vol.34, No. 2, 337344.

Baumeister, R. F., Shapiro, J. P., \& Tice, D. M. (1984). Two kinds of identity crisis. Journal of Personality, 53, 407-424.

Benard, B., (2004). Resiliency, what we have learned, WestEd, San Francisco, CA.

Berman, S. L., Weems, C. F., \& Stickle, T. R. (2006). Existential anxiety in adolescents: Prevalence, structure, association with psychological symptoms and identity development. Journal of Youth and Adolescence, 35, 303-310.

Berndt, T.J. (2004). Children's friendship: shift over a half century in perspectives on their development and their effects. Merrill-Palmer Quarterly, 50, 206-223.

Berzonsky, M.D., Macek, P., \&Nurmi, J. (2003). Interrelationships among identity process, content, and structure: Across-cultural investigation. Journal of Adolescent Research, 18(2), 112-130.

Beyers, W., \& Seiffge-Krenke, I. (2010). Does identity precede intimacy? Testing Erikson's theory on romantic development in emerging adults of the 21st century. Journal of Adolescent Research, 25, 387-415.

Blascovich, J., \& Tomaka, J. (1991). Measures of self-esteem. In J. P. Robinson, P. R. Shaver, \& L. S. Wrightsman (Eds.). Journal of Measures of Personality and Social Psychological Attitudes, Volume 1.San Diego, CA: Academic press.

Bosma, H.A. \& Kunnen, E.S. (2001).Determinants and mechanisms in ego identity development: A review and synthesis. Developmental Review, 21,39-66.

Breuer. (1973). Ego identity status in late adolescent college males, as measured by a groupadministered incomplete sentences blank and related to inferred stance toward authority. Unpublished doctoral dissertation, New York University, 1973.

Butman, R. E., \& Arp, J. H. (1990). Adolescent depression in its developmental and maturational context. Journal of Psychology and Christianity, 9(4), 34-43.

Clancy, S.M., \&Dolinger, S.J. (1993). Identity, self, and personality: I. Identity status and the five-factor model of personality. Journal of Research on Adolescence, 3(3), 227-245. 
Cramer, P. (2000). The development of identity: Gender makes a difference. Journal of Research in Personality, 34, 42-72.

Crocetti, E., Rubini, M., Meeus, W. (2008a).Capturing the dynamics of identity formation in various ethnic groups: Development and validation of a three-dimensional model. Journal of Adolescence, 31(2), 207-222.

DuBois, D.L., Burk-Braxton, C. Swenson, L.P. Tevendale ,H.D., Lockerd, E.M.,\&Moran ,B.L.(2002).Getting by a little help from self and others: self esteem and social support as resources during early adolescence. Developmental Psychology,36, 822-839.

Dumas, T. M., Lawford, H., Tieu, T., \& Pratt, M. W. (2009). Positive parenting and its relation to identity status in young adulthood: A longitudinal study. Developmental Psychology, 45, 1531-1544.

Erikson, E. (1950).Childhood and society. New York: Norton.

Erikson, E. (1968).Identity, youth and crisis. New York: Norton.

Farzaneh Khu, M.; Yarmohammadian, A. and Mowlavi, H., (2009). Influence of the overall performance of students on identified family status. Journal of Behavioral Sciences, 3(2): 142-135.

Fulton, A. S. (1997). Identity status, religious orientation, and prejudice. Journal of Youth and Adolescence, 26(1), 1-11.

Hashemi, Z. (2006) A study of the relationship between religious orientation (Islam) and identity types and dimensions in male and female students of Shiraz University. Master's Thesis, Shiraz University of Educational Sciences and Psychology.

Kenny, M.E., Gallagher, L.A., Alvarez-Salvat, R. \& Silsby, J. (2002). Sources of support and psychological distress among academically successful inner city youth. Adolescence, 37 ,161-182.

Kroger, J. (2003). Identity development during adolescence. In G. R. Adams \& M. D. Berzonsky(Eds.), Blackwell handbook of adolescence (pp. 205-226). Malden, MA: Blackwell.

Kroger, J., Martinussen, M., \& Marcia, J. E. (2010). Identity status change during adolescence and young adulthood: A meta-analysis. Journal of Adolescence, 33, 683-698.

Luyckx, K., Goossens, L., Soenens, B., Beyers, W., \& Vansteenkiste, M. (2005). Identity statuses based upon four rather than two identity dimensions: Extending and refining Marcia’s paradigm. Journal of Youth and Adolescence, 34, 605-618.

Luyckx, K., Schwartz, S. J., Berzonsky, M. D., Soenens, B., Vansteenkiste, M., Smits, I., et al. (2008). Capturing ruminative exploration: Extending the four-dimensional model of identity formation in late adolescence. Journal of Research in Personality, 42, 58-82.

Marcia, J. E. (1993). The status of the statuses: Research review. In J. E.Marcia, A. S.Waterman.

Marcia, J.E. (1966). Development and validation of ego-identity status. Journal of personality and social psychology, 3,551-558.

Marcia, J.E. (1967).Ego identity status: Relationship to change in self esteem. General maladjustment and authoritarianism. Journal of personality.1967, 35(1), 119-133.

Marcia, J.E. (1980). Identity in Adolescence. Handbook of Adolescence Psychology. New York. 
Matteson, D. R.; Archer, S. L.; \& Orlofsky, J. L. (Eds.). Identity: A handbook for psychosocial Research. New York: Springer-Verlag, (pp. 22-41).

McMullin, J.A. and Cairney, J. (2004). Self esteem and the intersection of age, class and gender. Journal of aging studies 18, 75-90.

Meeus, W. H. J.; Iedema, J.; Helsen, M.; \& Vollebergh, W. (1999). Patterns of adolescent identity development: Review of literature and longitudinal analysis. Developmental Review, 19, 419-461.

Nasiri, A.; Khosravi, SA; Ghaderi, Z; Vafayee, T; \& Esmaili, M. (2010). The effectiveness of group training of problem-solving on reducing identity crisis in female adolescents (veteran's children). J Veteran's

Omidian, M. (2009). Identity from the perspective of psychology. Yazd University Press.

Perlin, L. I.; Lieberman, M. A.; Menaghan, E. B.; \& Mullan, J. T. (1981). The stress process. Journal of Health and Social Behavior, 22, 337-356.

Podd, M.H. (1972). Ego identity status and morality: the relationship between two developmental constructs. Developmental psychology, 6, 497-507.

Pourghaznein, T. \& Ghafari, F. (2004) A study of hopefulness and its relationship with selfesteem of kidney transplant patients in Imam Reza Hospital. Sabzevar Faculty of Medical Sciences and Health Services, 11:61-55.

Raphael, D., Feinberg, R. \& Bachor, D. (1987). Student teachers' perceptions of the identity formation process. Journal of youth and adolescence, 16(4), 331-344.

Redenbach, S. (1991). Self-Esteem, The Necessary Ingredient for Success. USA: Esteem.

Robson, P.J. (1988). Self-esteem, a psychiatric view. British Journal of Psychiatry 1988; 113:615.

Rosenberg, M. (1965). Society and the adolescent self-image. Princeton, NJ: Princeton University Press.

Rosenberg, M. (1985). Self-concept and psychological well-being in adolescence. In R. L. Leahy (Ed.), The development of the self (pp. 205-246). Orlando, FL: Academic Press.

Rosenberg, M.; Schooler, C.; \& Schoenbach, C. (1989). Self-esteem and adolescent problems: Modeling reciprocal effects. American Sociological Review, 54, 1004-1018.

Sandhu, D. and Tung, S. (2004). Contributions of family environment and identity formation towards adolescent's alienation. Pakistan Journal of psychological research, 19(1-2), 114.Seminar Programs and Publications.

SarAbadaniTafreshi, L. (2006). The relationship between academic achievements, self-esteem and gender with anxity of computer among postgraduate of students in university of tabeiyat moallem tehran. University of Tabeiyat Moalem, Theran,Iran.

Schulenberg, J. E.; Sameroff, A. J.; \& Cicchetti, D. (2004). The transition to adulthood as a critical juncture in the course of psychopathology and mental health. Development and Psychopathology, 16, 799-806.

Schwartz, S. J., Zamboanga, B. L., Weisskirch, R. S., \& Rodriguez, L. (2009). The relationships of personal and ethnic identity exploration to indices of adaptive and maladaptive psychosocial functioning. International Journal of Behavioral Development, 33,131-144. 
Shahraray, M. (2005) Psychology of adolescents’ growth. Scientific Publication, Tehran.

Sherbaf, H., Sheikh, R.S. (2003).The process of identity formation, the effect of social factors, and identity treatment. Journal of Educational Sciences and Psychology, 1:199-226.

Streitmatter, J.L. (1987). Effect of gender and family status on ego-identity development among early adolescents. The Journal of Early Adolescence, 7, 179-189.

Taylor, R. \& Oskay, G. (1995). Identity formation in Turkish and American late adolescents.Journal of Cross-Cultural Psychology, 26, 8-22.

Taylor, S., \& Goritsas, E. (1994). Dimensions of identity diffusion. Journal of personality disorders, 8(3), 229-239.

Tesch, S. A., \& Cameron, K. A. (1987). Openness to experience and development of adult identity. Journal of Personality, 55, 615-630.

Thoits, P. (1999). Self, identity, stress, and mental health. In C. S. Aneshensel, \& J. C. Phelan (Eds.), Handbook of the sociology of mental health (pp. 345-368). New York: Kluwer Academic, Chapter 17.

Tung, S. and Kundra, N. (2012).Adolescent Identity Formation, Psychological Well-being, and Parental Attitudes. Pakistan Journal of Psychological Research, 2012, Vol. 27, No.1, 89105.

Tung, S. and Sandhu, D. (2005). Well-Being in Indian Adolescents: Role of Emotional Autonomy and Identity Formation. Pakistan Journal of Psychological Research Vol.20, Nos.3-4, 81-91.

Waterman, A. S. (2007). Doing well: The relationship of identity status to three conceptions of well-being. Identity: An International Journal of Theory and Research, 7, 289-307.

White, J.M., and Jones, R.J. (1996). Identity styles of male inmates. Criminal justice and behavior, 23,490-504.

Wires, J.W., Barocas, R., \& Hollenbeck, A.R. (1994). Determinants of adolescent identity development: A cross-sequential study of boarding school boys. Adolescence, 29 (114), 361-378. 